\title{
ALTAS HABILIDADES OU SUPERDOTAÇÃO E HABILIDADES SOCIAIS: ANÁLISE DE PRODUÇÕES NACIONAIS E INTERNACIONAIS
}

\author{
Helen Cristiane da Silva Theodoro* \\ Rosemeire de Araújo Rangni**
}

\begin{abstract}
RESUMO: O objetivo da presente pesquisa foi buscar e analisar produções acadêmicas nacionais e internacionais que versem sobre as Habilidades Sociais (HS) e pessoas com Altas Habilidades ou Superdotação (AHSD). Para tanto, foi realizada uma pesquisa bibliográfica, com busca em banco de dados acadêmicos nacionais e internacionais. Foram encontradas somente seis produções sobre o tema e a análise dos resultados apontou haver déficits em HS em pessoas com AHSD, principalmente na adolescência e na juventude. Assim, sugere-se mais pesquisas que averiguem os fatores que levam aos déficits em HS e que contribuam para melhorar a qualidade de vida dessas pessoas.
\end{abstract}

PALAVRAS-CHAVE: Altas Habilidades ou Superdotação; Habilidades Sociais; Educação Especial.

\section{HIGH ABILITIES OR GIFTEDNESS AND SOCIAL SKILLS: ANALYSIS OF NATIONAL AND INTERNATIONAL PRODUCTIONS}

\begin{abstract}
The aim of the present research was to search and analyze the national and international academic productions that deal with Social Skills (HS) and people with High Abilities or Giftedness (AHSD). To this end, a bibliographic search was carried out in national and international academic databases. Only six productions on the theme were found, and the analysis of the results pointed out that there are deficits of HS in people with AHSD, especially in adolescence and youth. Thus, more researches are suggested to investigate the factors that lead to HS deficits and they contribute to improve the quality of life of these people.
\end{abstract}

KEYWORDS: High abilities or Giftedness; Social Skills; Special Education.

* Mestranda em Educação Especial pelo Programa de Pós-Graduação em Educação Especial na Universidade Federal de São Carlos - UFSCar, helenstheodoro@gmail.com. Orcid: 0000-0003-0916-5429.

** Professora Adjunta do Departamento de Psicologia e do Programa de Pós-Graduação em Educação Especial da

Universidade Federal de São Carlos - UFSCar, rose.rangni@uol.com.br. Orcid: 0000-0002-8752-9745. 


\section{Introdução}

Os estudos sobre as pessoas com Altas Habilidades ou Superdotação (AHSD) ${ }^{1}$ têm se intensificado nos últimos anos. Todavia, em sua grande maioria, destacam aspectos educacionais que envolvem este público (FAVERI; HEINZLE, 2019; PÉREZ; FREITAS, 2011; RODRIGUÉZNAVEIRAS et al., 2019; ZAIA; NAKANO, 2020). Para além das questões acadêmicas, é importante ressaltar que as pessoas com AHSD são muito estigmatizadas, o que pode levar a possíveis déficits em Habilidades Sociais (HS) (ANTIPOFF; CAMPOS, 2010; CARNEIRO; FLEITH, 2017; CAMPOS, 2010; DOI; POLLI; AZEVEDO, 2018; PEREIRA; RANGNI, 2019; FLORES-BRAVO et al., 2018; PEDRO; OGEDA; CHACON, 2017).

As HS são um conjunto de comportamentos valorizados e que trarão benefícios individualmente e em grupo, considerando os contextos culturais em que essas pessoas estão inseridas. Desse modo, as HS são compostas por uma série de comportamentos verbais (o que se fala) e não verbais/paralinguísticos (aspectos como a postura, expressão facial, contato visual/físico, movimentos de cabeça, gestos, dentre outros), que implicarão na qualidade de vida, pois transmitem pelo desempenho (agressivo, passivo ou assertivo) as informações presentes nas relações interpessoais (DEL PRETTE, A.; DEL PRETTE, Z., 2017a, b).

Desse modo, a depender de como as pessoas com AHSD são identificadas e acompanhadas durante as fases do desenvolvimento (infância, adolescência, juventude e adulta), poderão ocorrer déficits em HS, como, por exemplo: a dificuldade de fazer novos amigos ou ter empatia (CHAGAS-FERREIRA et al., 2019; FOLEY-NICPON et al., 2017; ISHAK; ABIDIN; BAKAR; 2014; MARTINS, 2013).

Por essas razões, é importante compreender que as pessoas com AHSD podem ter potenciais e se desenvolverem para além da área acadêmica e, assim, podem necessitar de intervenções em HS nas diversas fases do desenvolvimento. Isso pode melhorar a qualidade das interações pessoais e, consequentemente, dos fatores inerentes ao desempenho em todas as áreas, quais sejam: intelectual, acadêmica, criatividade, liderança, artística e matemática (CHAGAS-FERREIRA et al., 2019; FOLEYNICPON et al., 2017; FRANÇA, 2012; OLIVEIRA, 2016).

Com relação às AHSD, os estudos, teorias e conceitos que envolvem as pessoas com capacidades além da média têm sido ampliados nas últimas décadas (GAGNÉ, 2015; RANGNI; COSTA, 2011; RENZULLI, 1998; VIRGOLIM, 2014). No entanto, no presente artigo abordaremos a Teoria dos Três Anéis do pesquisador norte-americano Joseph S. Renzulli, pois, trata-se, de um modelo que possui aplicabilidade e instrumentos que contribuem para a identificação e desenvolvimento das pessoas com AHSD (RENZULLI, 1998; 2004; 2005; 2014).

\footnotetext{
${ }^{1}$ Este estudo adota a terminologia "altas habilidades ou superdotação", de acordo com a Lei de Diretrizes e Bases da Educação Nacional (LDBEN) (BRASIL, 1996), entretanto, as terminologias usadas por autores e documentos oficiais serão mantidas.
} 
Ao explanar sobre o conceito de AHSD, Renzulli (1998; 2004; 2005; 2014) esclarece que seu foco não está somente em um campo teórico, mas em levantar mecanismos e instrumentos que possibilitem tanto a identificação quanto o fornecimento de um modelo para o enriquecimento do desenvolvimento das pessoas com AHSD.

Ao elucidar o que constitui as AHSD, Renzulli (2004; 2005; 2014) dispõe sobre as capacidades de criatividade e liderança, estabelecendo para isso um paralelo entre o propósito, a concepção e o programa a ser implementado. Esses fatores são relacionados com a forma e a metodologia de seu trabalho, pois uma das suas grandes marcas é a proposta do modelo de aplicabilidade para escolas, indo do teórico ao prático.

É por meio da construção teórica que Renzulli (2005) esclarece a concepção de AHSD pela Teoria dos Três Anéis. Ele elucida como sendo "a teoria que tenta mostrar as principais dimensões do potencial humano para a criatividade produtiva" (RENZULLI, 2005, p. 67). No que tange aos três anéis, eles representam a habilidade acima da média, o comprometimento com a tarefa e a criatividade, que estarão em intersecção, configurando o comportamento superdotado, e, interrelacionados com a personalidade da pessoa e os fatores ambientais. Os componentes dos anéis unidos estabelecem a superdotação e não podem ser considerados unitariamente.

Sobre a nova dimensão da Teoria de Três Anéis, Renzulli (2005) argumenta a respeito da liderança por ser um fator considerável relacionado às AHSD. Além disso, ele visou à implementação de um plano prático ao significar a identificação, o enriquecimento e a aceleração no desenvolvimento da pessoa com AHSD.

Seguindo nesta premissa, Renzulli (1998; 2004; 2005; 2014) traçou paralelos para a definição das AHSD. Para isso, fez relação entre superdotação e inteligência, ao afirmar que não se trata de uma questão unitária e que a inteligência é muito mais do que a quantidade de habilidades. Por sua vez, a AHSD não é uma herança, mas sim um processo contínuo de aquisição, em que devem ser realizadas avaliações das capacidades durante as fases de desenvolvimento.

Já em relação à inteligência, Renzulli $(2004 ; 2005$; 2014) relatou que não há uma única definição e um modo de medir o nível de inteligência das pessoas, o que pode levar à compreensão de que não há como medir a inteligência por meio de testes psicológicos.

Os debates sobre a inteligência realizados por Renzulli $(2005,2014)$ são o ponto de impulso para as discussões em razão das definições das AHSD. No tocante a isso, o autor estabeleceu duas categorias como base - superdotação escolar e criativo-produtiva -, que se tornam um mecanismo para o estabelecimento de instrumentos de identificação das pessoas com AHSD.

Neste sentido, a superdotação escolar é definida como a superdotação da testagem ou aprendizagem da lição, o que implica diretamente nos testes realizados na fase escolar e de acordo com o desenvolvimento acadêmico dos alunos, que se mostram e se mantêm acima da média diante de seus pares. Já a superdotação criativo-produtiva está além dos testes de quociente de inteligência (QI) e do 
rendimento escolar, mas desencadeia uma série de comportamentos de criatividade e produção, o que gera uma capacidade de alcançar feitos que serão socialmente relevantes, a partir de seu potencial (RENZULLI, 2005; 2014).

Complementando, ao realizar uma análise sobre a Teoria dos Três Anéis de Renzulli, Fernandes (2014) defendeu que há de se considerar os aspectos sociais e socioemocionais envolvidos na identificação das pessoas com AHSD, haja vista que são muitos os mitos e preconceitos enfrentados por estas pessoas, o que pode comprometer o desenvolvimento delas. Neste sentido, ascenderam-se novas dimensões à teoria, incluindo fatores cognitivos (a inteligência social, emocional, interpessoal e intrapessoal) que estão relacionados e independentes. Esse autor assevera que essa iniciativa foi motivada pelo papel que a educação de pessoas com AHSD deveria desempenhar para desenvolvimento do alto potencial na condução de liderança ética e responsável (Ibidem, 2005).

A falta de conhecimento e visibilidade em relação às pessoas com AHSD tem feito com que as construções sociais sejam respaldadas em mitos, estereótipos e preconceitos. Pesquisas se atentaram para esta finalidade, a fim de disseminar o conhecimento e esclarecer o máximo possível está temática, já que as pessoas com AHSD são, comumente, generalizadas como gênios; perfeitos; psicologicamente bem ajustados; adultos eminentes; pessoas que não precisarão de nenhum tipo de apoio ou acompanhamento socioemocional e/ou psicológico; estudantes impecáveis e insuperáveis; que têm destaque em todas as áreas; são excelentes em todos os contextos; entre outros (ANTIPOFF; CAMPOS, 2010; DOI; POLLI; AZEVEDO, 2018; PEDRO; OGEDA; CHACON, 2017; PERÉZ, 2011).

Freundlich (1987) corrobora esse entendimento ao acentuar, desde a década de 80, que as pessoas com AHSD fazem parte de uma população negligenciada pela sociedade, por conta da aceitação e do entendimento acerca dos estigmas e expectativas direcionados a elas. Assim sendo, declarou que seria necessário acompanhamento social e psicológico como forma de favorecer o pleno desenvolvimento deste público, o que pode influenciar diretamente no aprimoramento de sua HS.

Tratando-se de HS, a importância desse "campo de produção e aplicação do conhecimento" (DEL PRETTE, A; DEL PRETTE, Z., 2017b, p. 12) como um fator preditor de qualidade de vida e que, desenvolvido ainda na infância, implicará em um melhor desenvolvimento socioemocional e acadêmico. Esses fatores estão relacionados aos contextos familiares, interpessoais e afetivos, que estarão implicados nas demais fases do desenvolvimento, e podem ocorrer com maior ou menor qualidade, a depender da competência social do indivíduo, assinalam os citados autores, São conceitos-chave do campo das HS:

Desempenho social é qualquer tipo de comportamento que apresentamos na interação com outras pessoas e inclui tanto os que favorecem (habilidades sociais) como os que interferem na qualidade dos relacionamentos; Habilidades sociais são os comportamentos sociais, valorizados pela cultura ou subcultura nas interações com outras pessoas, que podem contribuir para a competência social; Competência social refere-se à efetividade do desempenho do indivíduo em uma interação social, ou seja, 
aos resultados da interação para o indivíduo e para seu grupo social, supondo, por princípio, a coerência entre o pensar, o sentir e o agir. (DEL PRETTE, A. DEL PRETTE, Z., 2017b, p. 14, grifos dos autores).

Tendo isso em vista, o desempenho social será mantido pelos comportamentos sociais desejáveis ou indesejáveis. Sobre os comportamentos sociais desejáveis, eles estão diretamente ligados ao conjunto de HS somados à competência social do indivíduo, os quais são voltados para o desempenho individual e para o grupo social. Os desempenhos sociais indesejáveis podem ser vistos como ativos ou passivos. Os ativos estão focados em comportamentos que são socialmente reprováveis, como agressão física e/ou verbal, mesmo que haja algum evento anterior que o justifique; e o passivo é aquele ocorrido pela inercia diante de situações sociais, como a "aceitação de injustiça, evitação, conformismo, desculpismo, dissimulação etc.” (DEL PRETTE, A.; DEL PRETTE, Z., 2017b, p. 16).

Outro ponto em destaque sobre as HS é que elas são situacionais, culturais e aprendidas. Em outros termos, as HS podem ser desenvolvidas e aprimoradas em todas as fases do desenvolvimento, a depender do contexto, da cultura e das demandas que são apresentadas. Como exemplo, uma pessoa terá seu conjunto de HS aprimorados e/ou desenvolvidos ao mudar de fase de desenvolvimento (da infância para adolescência), ir para uma nova escola, mudar de país, iniciar um novo relacionamento, se inserir no mercado de trabalho, entre outros aspectos. As classes de HS são: a) comunicação; b) civilidade; c) fazer e manter amizade; d) empatia; e) assertivas; f) expressar solidariedade; g) manejar conflitos e resolver problemas interpessoais; h) expressar afeto e intimidade; i) coordenar grupo; e j) falar em público (DEL PRETTTE, A.; DEL PRET'TE, Z., 2017a, b).

Diante disso, é possível compreender que as HS serão construídas dentro de um contexto cultural mais amplo; porém, há de se destacar que os microcontextos também podem ter impacto sobre as HS, desempenho e competência social. As relações familiares, educacionais, de trabalho, por exemplo, podem interferir nos comportamentos, pois passam valores éticos e morais que influenciarão em todo desempenho comportamental da pessoa. Pode, assim, ocorrer déficits em HS (DEL PRETTE, A.; DEL PRETTE, Z., 2017a).

Desde o nascimento, a família se esforça para passar valores morais e éticos (cultura) que irão influenciar em todos os fatores de convivência social. Ao iniciar as relações interpessoais, sejam com os pais, entre irmãos, demais familiares e terceiros, as pessoas aprendem e aperfeiçoam, geralmente por instruções, modelos e consequências novas HS, e, assim, aumentam sua competência social. No entanto, quando o ambiente não é favorável para o desenvolvimento, por inúmeros fatores, isso pode acarretar déficits nas HS e demandar futuras intervenções. Ou seja, poderá ocorrer o comprometimento da qualidade de vida (DEL PRETTE, A.; DEL PRETTTE, Z., 2017a).

Em se tratando de HS e pessoas com AHSD, França (2012), ao realizar uma revisão de literatura, apontou que existem inicialmente duas vertentes sobre as HS das pessoas com AHSD. A primeira estaria 
direcionada ao fato de que elas são consideradas excepcionais em todos os aspectos e que, por este motivo, possuem a capacidade de compreender melhor a si mesmo e aos outros. Esse fato pode estar relacionado ao mito de que pessoas com AHSD são bem ajustadas psicologicamente e não precisam de nenhum tipo de apoio (ANTIPOFF; CAMPOS, 2010; DOI; POLLI; AZEVEDO, 2018). Por outro lado, há uma crença que elas têm dificuldades em relacionamentos interpessoais e/ou afetivos, o que gera depressão, baixa autoestima, problemas comportamentais e, automaticamente, déficits em HS (FRANÇA, 2012).

Do ponto de vista acadêmico, Reis e Mccoach (2002) analisaram três décadas de pesquisa sobre o insucesso de alunos com AHSD. Sua pesquisa aferiu que esses alunos, por mais que apresentem habilidade acima da média, criatividade e envolvimento com a tarefa, são afetados por crises familiares, níveis socioeconômicos, baixa autoestima e depressão. Por isso, sugeriram com o estudo que seria importante o desenvolvimento de programas de intervenção familiar e educacional, com terapias individuais e em grupo. Essas intervenções seriam o melhor caminho para auxiliar o aluno com AHSD a se ajustar assertivamente no seu desempenho e competência social.

Flores-Bravo et al. (2018) analisaram as principais preocupações dos pais em relação aos filhos com AHSD. Seu estudo pontuou que os pais tendem a se preocupar com questões acerca do tédio, aprendizagem e relacionamentos sociais. Sobre os fatores educacionais, os pais demonstraram se preocupar com a escola, a classe em que o filho está inserido e os professores, pois acreditam que por seus filhos serem pessoas com AHSD podem se sentir deslocados, insatisfeitos e tornarem-se marginalizados. Além disso, os pais demonstraram preocupação com o ajuste social dos filhos, devido às relações interpessoais. Ademais, a pesquisa declarou ser essencial o acompanhamento dessas famílias e pessoas com AHSD com intervenções que potencializem e desenvolvam suas HS.

Contribuindo para essa prerrogativa, Rosal, Hernandéz-Jorge e Rodriguéz-Naveiras (2011) relataram que a falta de adaptação (ajuste social) das pessoas com AHSD é um mito e isso a prejudica em vários aspectos, inclusive no julgamento das famílias e dos professores. Também, direcionaram sua pesquisa aos adolescentes e eles constataram que, nesta fase do desenvolvimento, há um conjunto menor de HS devido à baixa autoestima, por ser recorrente a atribuição interna de êxito e fracasso em novas situações e contextos. Isso demandará programas de intervenção que permitam uma ampliação do repertório das HS, concomitantemente ao aumento do desempenho e da competência social dessas pessoas.

Levando esses apontamentos em consideração, esta pesquisa aborda as HS e AHSD, bem como a existência de pesquisas sobre a temática. Para tanto, foi realizado um levantamento de publicações nacionais e internacionais.

Diante do exposto e devido à importância do tema, questionou-se: existem produções cientificas nacionais e internacionais que abordem HS e AHSD? Assim, o objetivo do presente estudo foi buscar e 
analisar produções acadêmicas, nacionais e internacionais, que versem sobre as HS e as pessoas com AHSD.

\section{Método}

A pesquisa desenvolvida se caracteriza como sendo bibliográfica exploratória, que, segundo Marconi e Lakatos (2003), averigua e analisa o que foi tornado público em relação ao tema de estudo.

Para alcançar o objetivo traçado, foi realizada uma busca em bancos de dados acadêmicos nacionais e internacionais, que versassem sobre o tema em tela. Como critério de inclusão, as produções deveriam apresentar desde o título palavras que correspondessem à temática (HS e AHSD) e serem revisados por pares. Foram descartadas produções que abordassem somente HS ou AHSD como também artigos duplicados e derivados de teses e dissertações.

A pesquisa ocorreu no mês de março de 2021, sem recorte temporal. Para este fim, foram acessados os seguintes bancos de dados: Base de datos de Tesis Doctorales - TESEO; Biblioteca Digital de Teses e Dissertações - BDTD; Institut of Education Sciences - ERIC; Journals Oxford Academic; Portal de Periódicos Capes - MEC; Science Direct-ELSERVIER; Scientific Electronic Library Online - SCIELO; The Leadership Quarterly; Turkish Journal of Giftedness and Education - Türk Üstün Zeka ve Eğitim Dergisi.

Em relação às palavras-chave para a busca, foram utilizadas as seguintes: a) habilidades sociais AND altas habilidades; b) habilidades sociais AND superdotação; c) habilidades sociais AND dotação e talento. $\mathrm{O}$ operador booleano AND foi utilizado para unir o termo HS àqueles mais utilizados para se referir às pessoas com AHSD. As palavras foram traduzidas para a língua inglesa e espanhola para melhor se adequar aos campos de busca, a depender do site acessado, quais sejam: a) social skills AND high abilities; b) social skills AND giftedness; c) social skills AND endowment and talento; d) habilidades sociales $Y$ altas capacidades;

e) babilidades sociales $Y$ superdotación; f) habilidades sociales $Y$ superdotación y talento.

A seleção dos estudos passou por algumas etapas, conforme exposto no Quadro 1.

Quadro 1: Etapas e tarefas desenvolvidas na pesquisa.

\begin{tabular}{|c|c|}
\hline $\begin{array}{c}\text { Etapas } \\
\text { desenvolvidas } \\
\text { na pesquisa }\end{array}$ & Tarefas realizadas \\
\hline $\mathbf{1}$ & Busca das produções nos bancos de dados \\
\hline $\mathbf{2}$ & Leitura dos títulos, verificando se continha as palavras-chave da busca \\
\hline $\mathbf{3}$ & Leitura dos resumos \\
\hline $\mathbf{4}$ & Leitura dos textos na íntegra \\
\hline $\mathbf{5}$ & Elaboração de mapa conceitual dos textos encontrados, por banco de dados \\
\hline $\mathbf{6}$ & Junção das pesquisas encontradas em ordem cronológica \\
\hline $\mathbf{7}$ & Análise do conteúdo das pesquisas de acordo com o objetivo deste estudo \\
\hline
\end{tabular}

Fonte: Elaboração própria. 
Após esse processo, foram selecionadas as produções relevantes para a pesquisa e a análise dos dados foi realizada com base nos temas desenvolvidos e que pudessem alcançar os objetivos traçados neste estudo.

\section{Resultados e Discussão}

No Institut of Education Sciences - ERIC, a busca obteve 618 resultados. Filtrando por estudos em AHSD, oito resultados foram encontrados e, destes, um correspondia ao escopo deste artigo. O Science Direct - ELSEVIER apresentou 68 resultados e, destes, um era equivalente ao interesse da pesquisa. A Biblioteca Digital de Teses e Dissertações - BDTD retornou um total de 105 resultados. Três deles atendiam aos critérios de inclusão e foram selecionados. Já o Scientific Electronic Library Online - SCIELO apresentou 20 resultados, e somente quatro estavam relacionados com a proposta de trabalho.

Os demais bancos de dados - Base de datos de Tesis Doctorales - TESEO; Journals Oxford Academic, Portal de Periódicos Capes - MEC; The Leadership Quarterly; Turkish Journal of Giftedness and Education Türk. Üstün Zeka ve Eğitim Dergisi - não apresentaram resultados correspondentes ao objetivo da pesquisa e foram excluídos. Sendo assim, foram selecionados e analisados os trabalhos listados a seguir (Quadro 2).

Quadro 2: Resultado das pesquisas sobre HS e AHSD.

\begin{tabular}{|c|c|c|c|c|c|c|}
\hline 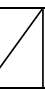 & Ano & Autores & Título & Tipo & $\begin{array}{c}\text { Banco de } \\
\text { dados }\end{array}$ & Periódicos \\
\hline 1 & 2012 & $\begin{array}{c}\text { Maria Luiza } \\
\text { Pontes de França }\end{array}$ & $\begin{array}{l}\text { Habilidades sociais e bem- } \\
\text { estar subjetivo de crianças } \\
\text { dotadas e talentosas }\end{array}$ & Tese & BDTD & - \\
\hline 2 & 2013 & $\begin{array}{c}\text { Cláudia Solange } \\
\text { Rossi Martins }\end{array}$ & $\begin{array}{c}\text { Análise das Habilidades } \\
\text { Sociais de adolescentes com } \\
\text { e sem indicadores de } \\
\text { dotação e influências } \\
\text { sociodemográficas }\end{array}$ & Tese & BDTD & - \\
\hline 3 & 2014 & $\begin{array}{c}\text { Noriah Mohd } \\
\text { Ishak; Mohd } \\
\text { Hakimie Zainal } \\
\text { Abidin; Abu Yazid } \\
\text { Abu Bakar } \\
\end{array}$ & $\begin{array}{l}\text { Dimensions of Social Skills and } \\
\text { their Relationship with Empatby } \\
\text { among Gifted and Talented } \\
\text { Students in Malaysia }\end{array}$ & Artigo & ELSEVIER & $\begin{array}{c}\text { Procedia-Social } \\
\text { and Behavioral } \\
\text { Sciences }\end{array}$ \\
\hline 4 & 2016 & $\begin{array}{c}\text { Ana Paula de } \\
\text { Oliveira }\end{array}$ & $\begin{array}{c}\text { Habilidades sociais e } \\
\text { problemas de } \\
\text { comportamento de } \\
\text { estudantes com altas } \\
\text { habilidades/superdotação: } \\
\text { caracterização, aplicação e } \\
\text { avaliação de um programa } \\
\text { de intervenção }\end{array}$ & Dissertação & BDTD & - \\
\hline 5 & 2017 & $\begin{array}{l}\text { Foley-Nicpon, } \\
\text { Megan; Assouline, } \\
\text { Susan G.; } \\
\text { Kivlighan, D. } \\
\text { Martin; } \\
\text { Fosenburg, Staci; } \\
\text { Cederberg, } \\
\text { Charles; Nanji, } \\
\text { Michelle }\end{array}$ & $\begin{array}{l}\text { The Effects of a Social and } \\
\text { Talent Development Intervention } \\
\text { for High Ability Youth with } \\
\text { Social Skill Difficulties }\end{array}$ & Artigo & ERIC & $\begin{array}{l}\text { Taylor e Francis } \\
\text { online. }\end{array}$ \\
\hline
\end{tabular}




\begin{tabular}{|c|c|c|c|c|c|c|}
\hline 6 & 2019 & $\begin{array}{c}\text { Jane Farias } \\
\text { Chagas-Ferreira; } \\
\text { Daniela Vilarinho- } \\
\text { Rezende; Renata } \\
\text { Muniz Prado; } \\
\text { Rayanne } \\
\text { Rodrigues de Lima }\end{array}$ & $\begin{array}{l}\text { Desenvolvendo Habilidades } \\
\text { Sociais com Jovens } \\
\text { Talentosos: Um Programa e } \\
\text { Múltiplas Experiências }\end{array}$ & Artigo & SCIELO & $\begin{array}{c}\text { Psic. Teoria e } \\
\text { Pesquisa }\end{array}$ \\
\hline
\end{tabular}

Fonte: Elaboração própria.

Em relação aos trabalhados selecionados, dois deles foram desenvolvidos com crianças (FRANÇA, 2012; OLIVEIRA, 2016), dois com adolescentes (ISHAK; ABIDIN; BAKAR; 2014; MARTINS, 2013) e dois com jovens (CHAGAS-FERREIRA et al., 2019; FOLEY-NICPON et al., 2017). Não houve retorno de trabalhos realizados com adultos com AHSD.

Verificou-se que duas produções se dedicaram a analisar as HS das pessoas com AHSD do ponto de vista acadêmico (ISHAK; ABIDIN; BAKAR; 2014; OLIVEIRA, 2016). Neste viés, a pesquisa de Oliveira (2016) se aprofundou, para além dos estudantes, a partir dos pais e professores dos alunos com AHSD. Para isso, descreveu as habilidades sociais e problemas de comportamento de estudantes com altas AHSD do ponto de vista dos próprios alunos (10 estudantes com AHSD, matriculados no Ensino Fundamental I), pais (10) e professoras (8). O estudo foi dividido em duas partes, na primeira foram realizadas as avaliações das HS dos três grupos de participantes e no segundo momento, aplicadas intervenções sobre as HS e avaliação do aumento do repertório delas. O primeiro estudo apontou que há um bom repertório nas HS dos estudantes, porém necessitam de intervenções nos déficits apresentados, como em afetividade, civilidade, autocontrole e comportamentos externalizantes. O segundo estudo esclareceu que os alunos se avaliaram piores do que seus próprios pais e professores e indicou baixa-autoestima; porém, com as intervenções eles tiveram ganhos em todos os fatores de HS.

Ishak, Abidin e Bakar (2014) estudaram sobre as dimensões das HS e sua relação com empatia entre alunos com AHSD na Malásia e tinham como objetivo verificar o quanto isso influenciava no desenvolvimento desses alunos. O estudo contou com 240 participantes ( 81 homens e 159 mulheres), de 15 anos que eram alunos do Centro Nacional de Superdotados da Malásia. Os participantes, cursavam o ensino médio e estavam em um programa de férias escolares. Os dados foram coletados por meio do Malaysian Emotional Quotient Inventory (MEQI), um instrumento desenvolvido pelos próprios pesquisadores. Os resultados apontaram que os alunos inicialmente tinham déficits nas HS de empatia, o que aumentou após o processo de aplicação do instrumento e orientação. Academicamente, os pesquisadores averiguaram que a empatia é um requisito muito importante para favorecer o desenvolvimento dos alunos individual e socialmente, sendo que aumenta a capacidade de gerir conflitos, trabalhar em cooperação e equipe, bem como em se comunicar eficazmente.

As demais (CHAGAS-FERREIRA et al., 2019; FRANÇA, 2012; FOLEY-NICPON et al., 2017; MARTINS, 2013) analisaram categorias de HS concernentes às questões afetivas, amizade, civilidade, assertividade e relações interpessoais. Esses estudos apontam a importância de compreender as 
habilidades sociais das pessoas com AHSD, o que pode auxiliar em todo seu desenvolvimento global, não somente focando nas questões acadêmicas.

Chagas-Ferreira et al. (2019) descreveram processos e resultados parciais relacionados a um Programa de Desenvolvimento de Habilidades Sociais para Jovens Talentosos (PDHSJT). Dentro deste programa, foram ofertadas onze turmas que atenderam 128 jovens com AHSD entre 2013 e 2015. As intervenções ocorreram em salas de Atendimento Educacional Especializado para AHSD e em um Centro de atendimento e estudos psicológicos da Universidade de Brasília/DF. As HS trabalhadas foram: civilidade, comunicação verbal e não-verbal, expressividade e autocontrole emocional, empatia e amizade, assertividade e cidadania, resolução de conflitos interpessoais. Os resultados mostraram que o PDHSJT foi essencial para o desenvolvimento e aprimoramento das HS dos jovens com AHSD, sendo que todos mostravam déficits em relação a isso. Consequentemente, houve aumento do repertório das HS trabalhadas.

França (2012) estudou as habilidades sociais e bem-estar subjetivo de crianças com AHSD, ditas pela autora como dotadas e talentosas. O objetivo do estudo foi caracterizar o repertório de HS e o nível de bem-estar subjetivo das crianças com AHSD e comparar esses níveis com outras crianças sem desenvolvimento acima da média. Participaram da pesquisa 394 crianças, sendo que 269 eram sinalizadas com AHSD e 125 eram identificados sem esta condição. As crianças frequentavam ensino regular e dois Centros de desenvolvimento do talento, em Lavras/MG e São José dos Campos/SP. Foram aplicados quatro instrumentos, que mediam: 1) repertório das habilidades sociais; 2) satisfação de vida; 3) afeto negativo e positivo; e 3) questionário sociodemográfico. Os resultados mostraram que as crianças com AHSD possuem maior repertório de habilidades sociais diante de seus pares.

A pesquisa de Foley-Nicpon et al. (2017) estudou quais os efeitos de uma intervenção de HS para o desenvolvimento de jovens com AHSD com dificuldades sociais. Participam do estudo 37 jovens com AHSD, porém não foi informada a idade de cada um deles ou a faixa etária estabelecida. Todos eram estudantes inscritos num programa de verão para desenvolvimento de talentos em uma universidade localizada na região centro-oeste dos Estados Unidos. Esses jovens participavam de atividades de acordo com sua área de interesse e relatavam terem dificuldades para interação social. A intervenção teve duração de 30 horas, executadas durante duas semanas. Os resultados apontaram que, quanto maior o desenvolvimento acadêmico mais dificultoso era, para os jovens, fazerem e manterem suas amizades. Esse fator, mostrou ser um déficit nas HS dos jovens com AHSD que melhoraram significativamente seu desempenho e competência social após a intervenção realizada.

O estudo realizado por Martins (2013) analisou as habilidades sociais de adolescentes com e sem AHSD e as influências sociodemográficas no que concerne a este público. Participaram da pesquisa 132 adolescentes (72 com AHSD e 60 sem indicadores de desenvolvimento acima da média), matriculados em quatro escolas de ensino regular e que frequentavam um Centro para o desenvolvimento do talento, localizados em Lavras/MG com idades entre 12 e 18 anos. Foram aplicados três instrumentos: 1) critério 
de classificação econômica; 2) formulário de dados acadêmicos; e 3) Instrumento de habilidades sociais para adolescentes. Os resultados apontaram que todos os níveis socioeconômicos eram equivalentes, não houve diferença significativa entre os grupos considerando a frequência das habilidades sociais, porém os adolescentes com AHSD apresentaram dificuldade na abordagem das habilidades sociais afetivas.

A respeito do aspecto metodológico, todas as produções avaliaram o repertório de HS dos respectivos participantes por meio de instrumentos previamente elaborados, como o Malaysian Emotional Quotient Inventory (MEQI), bem como roteiros de entrevistas e questionários de identificação desenvolvidos pelos próprios pesquisadores. Mesmo não sendo uma categoria direta de análise da atual pesquisa, foi possível verificar que após o processo de avaliação das HS, dois estudos relataram a importância de futuras intervenções (ISHAK; ABIDIN; BAKAR, 2014; MARTINS, 2013), um realizou um comparativo entre crianças com e sem AHSD (FRANÇA, 2012) e, três aplicaram intervenções com programas de HS para averiguar as possíveis mudanças nos participantes com AHSD (CHAGASFERREIRA et al.., 2019; FOLEY-NICPON et al.., 2017; OLIVEIRA, 2016).

Considerando a faixa etária dos participantes dos estudos, os resultados mostraram que apenas em crianças com AHSD o repertório de HS era maior do que seus pares (FRANÇA, 2012; OLIVEIRA, 2016). Em adolescentes e jovens, o repertório de HS apresentava déficits, principalmente no tocante aos relacionamentos interpessoais, afetividade e empatia (CHAGAS-FERREIRA et al., 2019; FOLEYNICPON et al., 2017; ISHAK; ABIDIN; BAKAR; 2014; MARTINS, 2013).

Os dados obtidos demonstraram a importância do desenvolvimento, aprimoramento e aumento do repertório de HS em pessoas com AHSD, haja vista que podem ocorrer déficits devido aos mitos enfrentados por elas. De todo modo, as pesquisas relataram a importância de: a) programas de intervenção de HS que sejam direcionados às AHSD; b) acompanhamento e participação da família; c) acompanhamento e participação dos professores; d) análise dos ambientes internos e externos que fazem parte do desenvolvimento da pessoa com AHSD e que podem influenciar no aprimoramento e desenvolvimento das HS (CHAGAS-FERREIRA et al., 2019; FRANÇA, 2012; FOLEY-NICPON et al., 2017; ISHAK; ABIDIN; BAKAR; 2014; MARTINS, 2013; OLIVEIRA, 2016).

Os estudos têm mostrado que, após o processo de identificação das pessoas com AHSD, pode ocorrer uma cobrança e/ou expectativa excessiva sobre o desempenho delas. Esses fatores estão diretamente ligados aos mitos de que esses indivíduos são gênios e que por nenhum motivo experimentarão o fracasso (ANTIPOFF; CAMPOS, 2010; CHAGAS-FERREIRA et al., 2019; DOI; POLLI; AZEVEDO, 2018; PEDRO; OGEDA; CHACON, 2017; PERÉZ, 2011).

Essas afirmações podem ser analisadas se observarmos a diferença entre as faixas-etárias dos estudos encontrados. Quando o estudo foi realizado com crianças com AHSD de menor idade, elas apresentaram um repertório maior de HS em relação aos seus pares; todavia, quando avançaram no 
processo de desenvolvimento (maior idade) déficits de HS foram sendo observados (FRANÇA, 2012; OLIVEIRA, 2016).

Em se tratando das crianças com AHSD, uma possibilidade é que, após a identificação, os pais tendem a acreditar que a excepcionalidade dos filhos os fará ter sucesso em toda sua trajetória de vida. Outro ponto a ser levantado é que geralmente as famílias tendem em demandar mais atenção nesta fase do desenvolvimento (infância) e, por isso, os déficits em HS começam a se tornar mais evidentes após a adolescência, momento em que, de modo geral, as pessoas começam a se tornar mais independentes (FOLEY-NICPON et al., 2017; MARTINS, 2013). Em adolescentes e jovens com AHSD, os déficits em HS também eram muito maiores do que quando crianças, o que pode estar relacionado ao fato que o ambiente não esteja totalmente favorável ao pleno desenvolvimento e à qualidade de vida dessas pessoas (CHAGAS-FERREIRA et al., 2019).

No entanto, as HS são influenciadas pelo macro e microcontexto (DEL PRETTE, A.; DEL PRETTE, Z., 2017a). Em outras palavras, para além da cultura em que se está inserido, as questões individuais, familiares, acadêmicas, de relacionamento etc. terão grande interferência sobre o desempenho do sujeito em relação às suas HS. Essa constatação pode ser analisada no estudo de Oliveira (2016), em que alunos com AHSD se avaliaram piores do que seus próprios pais e professores, ou seja, a crença e expectativa depositada nessas pessoas poderiam estar sendo excessivas, a ponto de causar a baixa autoestima e déficits nas HS de afetividade, civilidade, autocontrole e comportamentos externalizantes.

Uma constatação importante em relação aos estudos analisados e à teoria na área foi que a pesquisa de Flores-Bravo et al. (2018) apontou as preocupações dos pais no tocante aos filhos com AHSD tanto com os assuntos educacionais quanto de relacionamentos interpessoais. Mesmo os pais tendo aferido suas inquietações sobre o desenvolvimento e a qualidade de vida de seus filhos, isso não quer dizer que algo esteja sendo feito para ampliar e melhorar as HS deles, pois em outros estudos que versam diretamente sobre as pessoas com AHSD verificaram-se déficits em HS, confirmando, assim, o disposto por Freundlich (1987), em que pessoas com AHSD são, de alguma forma, negligenciadas pela sociedade.

Ademais, notou-se que os déficits em HS das pessoas com AHSD estão direcionados às questões socioemocionais. Nas produções selecionadas, foram verificados que os déficits são, principalmente, nas HS de civilidade; comunicação verbal e não-verbal/paralinguísticos; expressividade; autocontrole emocional; empatia; amizade; assertividade; cidadania; resolução de conflitos interpessoais; expressar afeto e intimidade. Entretanto, fatores sociodemográficos não interferiram no aumento ou diminuição do repertório de HS desses sujeitos (CHAGAS-FERREIRA et al., 2019; FRANÇA, 2012; FOLEYNICPON et al., 2017; ISHAK; ABIDIN; BAKAR; 2014; MARTINS, 2013; OLIVEIRA, 2016).

Seguindo nesta direção, Rosal, Hernandéz-Jorge e Rodriguéz-Naveiras (2011) acentuam que a falta de adaptação em pessoas com AHSD é decorrência da baixa autoestima e das recorrentes cobranças externas e internas em relação ao êxito e fracasso. Sendo assim, pode-se haver uma possível justificativa dos déficits em HS que foram apresentados pelas pessoas com AHSD nos estudos analisados. 
Em vista disso, Renzulli (2004; 2005; 2014), ao tratar da AHSD por meio de duas categorias base - superdotação escolar e criativo-produtiva -, assinala a importância de saber que as pessoas com AHSD apresentam demandas em todas as áreas do desenvolvimento, e não somente na área acadêmica. Isso se reflete em várias situações, mas, principalmente, em déficits em HS, pois, mantendo-se o foco na área educacional, negligenciam seus fatores socioemocionais. Verifica-se essa colocação ao analisar os resultados encontrados no disposto por Foley-Nicpon et al. (2017) e Reis e Mccoach (2002), que constataram que, se alguém é motivado academicamente a superar seus pares, isso pode afetar negativamente sua capacidade de formar laços estreitos com os colegas. Logo, podem ocorrer prejuízos socioemocionais, sendo essencial o desenvolvimento de programas de intervenção para aprimorar suas HS e melhorar seus relacionamentos interpessoais.

Todos os resultados pontuaram de maneira incisiva a importância de serem realizados programas de intervenção em HS nas pessoas com AHSD. Naqueles em que ocorreram intervenções, houve aumento significativo no repertório de HS, desempenho, competência social e melhora na qualidade de vida (CHAGAS-FERREIRA et al., 2019; FRANÇA, 2012; FOLEY-NICPON et al., 2017; ISHAK; ABIDIN; BAKAR; 2014; MARTINS, 2013; OLIVEIRA, 2016). Desta forma, infere-se, que seria necessário ampliar o olhar para esta temática, compreendendo que pessoas com AHSD não podem ser visualizadas somente por competências em disciplinas acadêmicas, pois, é recomendável atentar para outras capacidades dos estudantes; a liderança, por exemplo, na qual habilidades interpessoais são demonstradas. A esse respeito, Renzulli (2005) assinala que fatores co-cognitivos devem ser considerados no ambiente escolar, desse modo, as intervenções junto a esse público serão viáveis. Para tanto, é importante que os mitos acerca desse grupo de pessoas sejam sanados e as questões socioemocionais estejam estabelecidas de forma assertiva.

\section{Considerações finais}

Os estudos sobre AHSD têm se ampliado nas últimas décadas, principalmente aqueles voltados a contextos educacionais, políticas e identificação. Porém, ainda são poucas as pesquisas que abordam os aspectos socioemocionais dessas pessoas.

Atendendo ao objetivo proposto, o levantamento em bancos nacionais e internacionais de produções científicas resultou em seis pesquisas que versaram sobre a temática das HS e AHSD. A análise dos resultados aferiu que, com o avanço nas fases do desenvolvimento da infância para a juventude, $o$ repertório de HS das pessoas com AHSD tende a apresentar déficits, principalmente relacionados à empatia e à afetividade.

Considera-se que os déficits encontrados acerca das HS em pessoas com AHSD podem estar associados aos mitos em torno dessas pessoas. Ademais, situações de extrema cobrança e altas 
expectativas sobre o desempenho podem ocasionar episódios de depressão, baixa autoestima e, consequentemente, uma diminuição no repertório de HS.

Seriam necessários, para além do foco acadêmico, estudos que almejassem compreender as demandas socioemocionais das pessoas com AHSD ao longo das fases de desenvolvimento, pois, como verificado, mudanças de ambiente, cobranças excessivas, expectativas altas, crises familiares ou de relacionamentos podem ser algumas das causas dos déficits em HS. Ademais, seria necessário compreender os fatores que levam ao aumento de déficits após a infância.

A partir das reflexões dos dados obtidos, sugerem-se intervenções em HS tanto com as pessoas com AHSD quanto com os pais, familiares e professores. O aprimoramento e o aprendizado de HS podem contribuir para que pessoas com AHSD tenham mais autoestima, autocuidado, desempenho e competência social, o que trará benefícios individuais e para os grupos em que estão inseridos.

\section{REFERÊNCIAS}

ANTIPOFF, Cecília Andrade; CAMPOS, Regina Helena de Freitas. Superdotação e seus mitos. Revista Semestral da Associação Brasileira de Psicologia Escolar e Educacional, SP, v. 14, n. 2, jul./dez., 2010, p. 301309. Disponível em: http://www.scielo.br/pdf/pee/v14n2/a12v14n2.pdf. Acesso em: 05 fev. 2019.

BRASIL. Lei ñ 9.394, de 20 de dezembro de 1996. Estabelece a Lei de Diretrizes e Bases da Educação Nacional. Disponível em: http://www.planalto.gov.br/ccivil 03/leis/19394.htm. Acesso em: 10 out. 2020.

CARNEIRO, Liliane Bernardes; FLEITH, Denise de Souza. Panorama brasileiro do atendimento ao aluno superdotado. Revista de Estudios e investigación em Psicología y Educación. v. Extr., n. 11, 2017. Disponível em: http://revistas.udc.es/index.php/reipe/article/view/reipe.2017.0.11.2926. Acesso em: 05 fev. 2019.

CHAGAS-FERREIRA, Jane Farias et al. Desenvolvendo Habilidades Sociais com Jovens Talentosos: Um Programa e Múltiplas Experiências. Psic.: Teor. e Pesq., Brasília, v. 35, 2019. Disponível em: https://www.scielo.br/j/ptp/a/GJjJWWfN59yQpYGSHRnZFQH/?lang=pt. Acesso em: 10 out. 2020.

DEL PRETTE, Almir; DEL PRETTE, Zilda Aparecida Pereira. Competência Social e Habilidades Sociais: manual teórico-prático. Petrópolis: Vozes, 2017a. 252 p.

DEL PRETTE, Almir; DEL PRET'TE, Zilda Aparecida Pereira. O campo das Habilidades Sociais: conceitos básicos e importância. In: DEL PRETTTE, Almir; DEL PRETTE, Zilda Aparecida Pereira. (Orgs.). Habilidades Sociais e Competência Social para uma vida melhor. São Carlos: EdUFSCar, 2017b, p. 7-24.

DOI, Francislaine Wiczneski; POLLI, Gislei Mocelin; AZEVÊDO, Adriano Valério dos Santos. Mitos e representações sobre altas habilidades/superdotação: revisão sistemática. Psicol. Argum., vol. 36, nº 93, 
2018, p. 275-295. Disponível em:

https://periodicos.pucpr.br/index.php/psicologiaargumento/article/view/24745/23766. Acesso em: 15 mar. 2021.

FAVERI, Fanny Bianca Mette de; HEINZLE, Marcia Regina Selpa. Altas Habilidades/Superdotação: políticas visíveis na educação dos invisíveis. Revista Educação Especial, v. 32, 2019. Disponível em: https://periodicos.ufsm.br/educacaoespecial/article/view/39198/html. Acesso em: 15 mar. 2021.

FERNANDES, Tereza Liduina Grigório. Teoria triádica da superdotação: habilidades superiores, criatividade e motivação. Didática e Prática de Ensino na relação com a sociedade, EDUEC, livro 3, n ${ }^{\circ}$ 03860, 2014, p. 1-9. Disponível em: https://silo.tips/download/teoria-triadica-da-superdotaaohabilidades-superiores-criatividade-e-motivaao. Acesso em: 18 mar. 2021.

FLORES-BRAVO, Juan Francisco et al. Principales preocupaciones de padres de hijos con altas capacidades. Revista de Educación y Desarrollo, no 47, 2018, p. 115-122. Disponível em: https://www.cucs.udg.mx/revistas/edu desarrollo/anteriores/47/47 Flores.pdf. Acesso em: 15 mar. 2021.

FOLEY-NICPON, Megan ; ASSOULINE, Susan ; KIVLIGHAN, Martin ; FOSENBURG, Staci; CEDERBERG, Charles; NANJI, Michelle. The effects of a social and talent development intervention for high ability youth with social skill difficulties. Taylor \& Francis Online, v. 28, 2017, p. 73-92.

Disponível em: https://www.tandfonline.com/doi/abs/10.1080/13598139.2017.1298997. Acesso em: 15 mar. 2021.

FREUNDLICH, Dale Joan. The Gifted: An Underserved Minority Population. Children \& Schools, v. 10, n.1, 1987, p. 43-59. Disponível em: https://academic.oup.com/cs/articleabstract/10/1/43/383280? redirectedFrom=fulltext. Acesso em: 20 mar.2021.

GAGNÉ, Françoys. From genes to talent: the DMGT/CMTD perspective. Revista de Educación, n. 368, april./jun., 2015, p. 12-37. Disponível em:

https://www.researchgate.net/publication/281951734 From genes to talent the DMGTCMTD pe rspective. Acesso em: 14 set. 2021.

ISHAK, Noriah Mohd; ABIDIN, Mohs Hakimie Zainal; BAKAR, Abu Yazid Abu. Dimensions of social skills and their relationship with empathy among gifted and talented students in Malaysia. Procedia - Social and Behavioral Sciences, n.116, p. 750-753, 2014. Disponível em: https://www.semanticscholar.org/paper/Dimensions-of-social-skills-and-their-relationshipIshakAbidin/d6d6f17f8a9d4c8a31e6dd7f2519d9acd384de16. Acesso em 11 de set. 2020.

MARCONI, Marina de Andrade; LAKATOS, Eva Maria. Fundamentos de Metodologia Cientifica. 5. ed., Atlas, São Paulo, 2003, 311 p.

MARTINS, Cláudia Solange Rossi. Análise das habilidades sociais de adolescentes com e sem indicadores de dotação e influências sociodemográficas. 2013. 260 f. Tese (Doutorado em Ciências Humanas) - Universidade Federal de São Carlos, São Carlos, 2013. Disponível em: https://repositorio.ufscar.br/bitstream/handle/ufscar/2912/5133.pdf?sequence=1\&isAllowed $=\mathrm{y}$. Acesso em: 11 set. 2020.

OLIVEIRA, Ana Paula de. Habilidades sociais e problemas de comportamento de estudantes com altas habilidades/superdotação: caracterização, aplicação e avaliação de um programa de intervenção. 2016. 135 f. Dissertação (Mestrado em Psicologia do Desenvolvimento). Universidade Estadual Paulista "Júlio de Mesquita Filho". Bauru/SP. 2016. Disponível em:

https://repositorio.unesp.br/handle/11449/144433. Acesso em: 11 set. 2020. 
PEDRO, Ketilin Mayara; OGEDA, Clarissa Maria Marques; CHACON, Miguel Cláudio Moriel. Verdadeiro ou falso? Uma análise dos mitos que permeiam a temática das altas habilidades/ superdotação. Revista Educação e Emancipação, São Luís, v. 10, n. 3, set/dez., 2017. Disponível em: http://www.periodicoseletronicos.ufma.br/index.php/reducacaoemancipacao/article/view/7718. Acesso em: 05 fev. 2019.

PEREIRA, Josilene Domingues Santos; RANGNI, Rosemeire de Araújo. Cenas do filme "O Jogo da imitação": reflexões sobre a invisibilidade da dupla excepcionalidade no contexto social. Aprender: Cad. de Filosofia e Psic. da Educação, Vitória da Conquista, v. 13, n. 21, jan./jun., 2019, p. 76-89. Disponível em: https://periodicos2.uesb.br/index.php/aprender/article/view/5608. Acesso em: 05 abr. 2021.

PÉREZ, Susana Graciela Pérez Barrera. O culto aos mitos sobre as altas habilidades/superdotação? Psicol. Argum., v. 29, n. 67, out./dez., 2011, p. 513-531. Disponível em:

https://periodicos.pucpr.br/index.php/psicologiaargumento/article/view/20413/19677. Acesso em: 15 mar. 2021.

PÉREZ, Susana Graciela Pérez Barrera; FREITAS, Soraia Napoleão. Encaminhamentos pedagógicos com alunos com Altas Habilidades/Superdotação na Educação Básica: o cenário brasileiro. Educar em Revista, n. 41, 2011. Disponível em: https https://www.scielo.br/pdf/er/n41/08.pdf. Acesso em: 18 mar. 2021.

RANGNI, Rosemeire de Araújo; COSTA, Maria Piedade Resende da. Altas habilidades/superdotação: entre termos e linguagens. Revista Educação Especial, v. 24, n. 41, set./dez. 2011. Disponível em: https://periodicos.ufsm.br/educacaoespecial/article/view/3056. Acesso em: 15 fev. 2019.

REIS, Sally M.; MCCOACH, Betsy. The underachievement of gifted students: what do we know and where do we go? Gifted Child Quarterly, v. 44, n. 3, 2000, p.152-170. Disponível em: https://scihub.se/https://doi.org/10.1177\%2F001698620004400302. Acesso em: 14 set. 2021.

RENZULLI, Joseph Salvatore. Three ring conception of giftedness. In: BAUM, Susan; REIS, Sally M; MAXFIELD, Lori R. (Eds.). Nurturing the gifts and talents of primary grade students. Mansfield Center, CT: Creative Learning Press, 1998.

RENZULLI, Joseph Salvatore. The Three-Ring Conception of Giftedness: A Developmental Model For Promoting Creative Productivity. In: STERNBERG, Robert J.; DAVIDSON, Janet E. Conceptions of Giftedness. Cambridge University Press, New York, Ed.2, 2005, p. 246-279.

RENZULLI, Joseph Salvatore. The schoolwide enrichment model: a comprehensive plan for the development of talents and giftedness. Revista Educação Especial, v. 27, n. 50, set./dez., 2014, p. 539-562. Disponível em: https://periodicos.ufsm.br/educacaoespecial/article/view/14285. Acesso em: 20 mar. 2021.

RENZULLI, Joseph Salvatore. O que é esta coisa chamada superdotação, e como a desenvolvemos? Uma retrospectiva de vinte e cinco anos Educação. Pontifícia Universidade Católica do Rio Grande do Sul, Porto Alegre, Brasil, vol. XXVII, n. 52, jan./abr., 2004, p. 75-131. Disponível em: https://www.redalyc.org/pdf/848/84805205.pdf. Acesso em: 22 mar. 2021.

RODRÍGUEZ-NAVEIRAS, Elena; CADENAS, Maria; BORGES, África; VALADEZ, Dolores. Educational responses to students with high abilities from the parental perspective. Frontiers in psychology, v. 10, n. 1187, mai., 2019, p. 1-18. Disponível em: https://www.ncbi.nlm.nih.gov/pmc/articles/PMC6543867. Acesso em: 20 mar. 2021. 
ROSAL, África Borges Del; HERNÁNDEZ-JORGE, Carmem; RODRÍGUEZ-NAVEIRAS, Elena. Evidencias contra el mito de la inadaptación de las personas con altas capacidades intelectuales. Psicothema, v. 23, n. 3, 2011, p. 362-367. Disponível em: http://www.psicothema.com/pdf/3895.pdf. Acesso em: 19 mar. 2021.

VIRGOLIM, Angela Mágda Rodrigues. A inteligência em seus aspectos cognitivos e não cognitivos na pessoa com altas habilidades/superdotação: uma visão histórica. In: VIRGOLIM, Angela Mágda Rodrigues; KONKIEWITZ, Elisabete Castelon (Orgs.) Altas habilidades/superdotação, inteligência e criatividade: uma visão multidisciplinar. Campinas, SP: Papirus, 2014, p. 23-64.

ZAIA, Priscila; NAKANO, Tatiana de Cássia. Escala de Identificação das Altas Habilidades/Superdotação: Evidências de Validade de Critério. Revista Iberoamericana de Diagnóstico y Evaluación - e Avaliação Psicológica. RIDEP, v. 2, n. 55, 2020, p. 31-41. Disponível em: https://www.aidep.org/sites/default/files/2020-04/RIDEP55-Art3.pdf. Acesso em: 15 mar. 2021. 